aneurysm carries a low risk of perioperative stroke $(0.84 \%)$ compared with a standard left thoracotomy approach $(3.3 \%-8.1 \%)^{5}$ Manipulation of the aortic arch by using techniques such as crossclamping is thought to be a predisposing factor for stroke. In our patients a right thoracotomy with crossclamping of the aorta just distal to the right carotid artery was one possible surgical approach that could have been considered. However, we chose to perform total arch replacement through a midsternotomy with DHCA, and this was accomplished with no neurologic complications. Through a midsternotomy, it was easy to cannulate and reconstruct the arch vessels, including the ALSA. We completed the distal anastomosis by using an elephant trunk technique, even under the conditions of limited exposure provided by the midsternotomy. However, if the aneurysm had involved a large segment of the descending aorta or the patient had been very large, it would have been difficult to perform the distal anastomosis through a median sternotomy alone, and it might have been necessary to consider an additional right thoracotomy or two-stage operation (total arch replacement, followed by descending thoracic aorta replacement).

In conclusion, total arch replacement with DHCA through a midsternotomy alone is a useful approach for surgical repair of a right-sided aortic arch aneurysm with an ALSA in terms of brain protection and reconstruction. Surgical management for a normal left-sided distal arch aneurysm is applicable to a right-sided aortic arch aneurysm with an ALSA.

\section{References}

1. Knight L, Edwards JE. Right aortic arch. Types and associated cardiac anomalies. Circulation. 1974;50:1074-51.

2. Svensson LG, Crawfor DS. Congenital abnormalities of the aorta in adults. In: Svensson LG, Crawford DS, editors. Cardiovascular and vascular disease of the aorta. Philadelphia: WB Saunders; 1997. p. 153-74.

3. Tsukube T, Ataka K, Sakata M, Wakita N, Okita Y. Surgical treatment of an aneurysm in the right aortic arch with aberrant left subclavian artery. Ann Thorac Surg. 2001;71:1710-1.

4. Robinson BLAC, Nadolny EM, Entrup MH, Svensson LG. Management of right-sided aortic arch aneurysms. Ann Thorac Surg. 2001;72: $1764-5$.

5. Minatoya K, Ogino H, Matsuda H, Sasaki H, Yagihara T, Kitamura S. Surgical management of distal arch aneurysm: another approach with improved results. Ann Thorac Surg. 2006;81:1353-7.

\title{
Wound complications associated with the submammary incision for repair of congenital heart defects in female patients
}

\author{
Victor 0. Morell, MD, Peter D. Wearden, MD, PhD, and Mahesh S. Sharma, MD, Pittsburgh, Pa
}

T o improve the cosmetic result of the standard vertical median sternotomy incision, William and Hanlon ${ }^{1}$ in 1960 introduced the transverse submammary incision for median sternotomy. This operative approach has proved especially useful for female patients undergoing simple cardiac surgical procedures, resulting in a more esthetically pleasing scar. Although used in some centers, it has not gained worldwide popularity because of concerns related to potential wound complications, adequacy of surgical exposure, and access for reoperation. We have reviewed our experience with the submam-

From Children's Hospital of Pittsburgh, University of Pittsburgh, Pittsburgh, $\mathrm{Pa}$.

Received for publication July 31, 2006; accepted for publication Aug 7, 2006.

Address for reprints: Victor O. Morell, MD, Chief, Cardiothoracic Surgery, Children's Hospital of Pittsburgh, Associate Professor of Surgery, University of Pittsburgh, Room 2820, 3705 Fifth Ave, Pittsburgh, PA 15213 (E-mail: victor.morell@chp.edu).

J Thorac Cardiovasc Surg 2006;132:1475-6

$0022-5223 / \$ 32.00$

Copyright $\odot 2006$ by The American Association for Thoracic Surgery doi:10.1016/j.jtcvs.2006.08.004 mary incision in more than 100 patients undergoing repair of simple and complex congenital heart lesions.

\section{Patients and Methods}

This was a retrospective analysis of 106 consecutive female patients undergoing cardiac surgical procedures through the submammary approach for congenital heart defects. Their ages, surgical procedures, reoperations, and wound complications were examined.

A transverse surgical incision, extending from anterior axillary line to anterior axillary line, was performed at the level of the inferior mammary crease when present, or alternatively at the level of the xiphisternal joint in younger patients. The superior skin flap was created with electrocautery to the level of the sternal notch. Once the sternum was divided and the sternal retractor was placed, the skin flap was retracted superiorly with a self-retaining retractor. At the time of wound closure, a subcutaneous drain was placed under the superior skin flap in all cases.

\section{Results}

The mean patient age was 3.9 years (range 1 month -44 years). The surgical procedures, recorded in Table 1, included both simple and complex operations. There were no deaths in this group. Wound complications (Table 2) included seroma formation in 5 patients (4.5\%), superficial wound infection in 2 patients $(1.8 \%)$, hematoma formation in 1 patient $(0.9 \%)$, and partial superior skin flap 
TABLE 1. Surgical procedures

\begin{tabular}{lc}
\hline Procedure & No. \\
\hline Atrial septal defect repair & 40 \\
Ventricular septal defect repair & 21 \\
Tetralogy of Fallot repair & 15 \\
Complete atrioventricular canal repair & 13 \\
Subaortic membrane resection & 3 \\
Mitral valve repair & 3 \\
Double-outlet right ventricle repair & 3 \\
Coronary artery fistula repair & 2 \\
Double-chamber right ventricle repair & 2 \\
Aortopulmonary window repair & 1 \\
Hypoplastic aortic arch repair & 1 \\
Aortic root replacement & 1 \\
Blalock-Taussig shunt & 1 \\
\hline
\end{tabular}

necrosis in 1 patient $(0.9 \%)$. Five patients underwent reoperation through a previous transverse submammary incision with no wound complications.

\section{Discussion}

During the last decade, there has been a renewed interest in improving the cosmetic results of cardiac surgical incisions, especially in female patients. Our preference has been to offer the submammary incision to female patients to avoid the unattractive scar associated with the standard vertical median sternotomy incision.

Although first described more than 40 years ago, the use of the submammary incision in cardiac surgery is still associated with concerns regarding surgical exposure, wound complications, and breast development. As with others, ${ }^{2-5}$ we have found that this surgical approach provides excellent exposure of the mediastinum, thus allowing the repair of both simple and complex congenital heart lesions. Although only a small number of patients $(n=5)$ underwent reoperations through a reopened submammary incision, we found no increase incidence of wound complications in this group. This agrees with the findings of Odim and associates, ${ }^{2}$ who reported on a series of 15 patients undergoing cardiac operations through a reopened submammary incision with minimal complications.

We observed a low incidence of wound complications with this type of incision in our series. The most frequent problem noted
TABLE 2. Observed complications

\begin{tabular}{lcc}
\hline Complications & No. & $\%$ \\
\hline Seroma & 5 & 4.5 \\
Superficial wound infection & 2 & 1.8 \\
Subcutaneous hematoma & 1 & 0.9 \\
Partial flap necrosis & 1 & 0.9 \\
\hline
\end{tabular}

was the development of a seroma underneath the superior skin flap. These cases were treated with the placement of a subcutaneous drain, which was then managed on an outpatient basis. One patient had a small area of skin necrosis develop in the central portion of the superior flap; this was thought to be related to excessive upward traction of the skin flap.

Although we did not assess breast development in our patient population, other centers ${ }^{3,5}$ have reported normal breast development and function after a submammary incision. An incision that avoids the breast tissue is an important factor in promoting normal, symmetric breast development. ${ }^{5}$ One of the concerns with this approach in neonates, infants, and young female patients is where to place the incision to avoid the breast tissue. For these patients, we have opted to place a horizontal incision at the level of the xiphisternal junction, which should be safely below the inferior mammary crease and sufficiently removed from breast tissue.

In conclusion, the submammary incision provides a sensible alternative to the standard vertical median sternotomy incision for female patients undergoing repair of a congenital cardiac lesion. It results in an esthetically located scar with a low incidence of wound complications.

\section{References}

1. Willman VL, Hanlon CR. Median sternotomy using a transverse submammary skin incision. Am J Surg. 1960;100:779-81.

2. Odim J, Vyas R, Laks H, Alikhani A, Mehta U, Hughes K. Redo submammary incision for median sternotomy and cardiac repair. Ann Thorac Surg. 2005;79:163-7.

3. Deutinger M, Domanig E. Breast development and areola sensitivity after submammary skin incision for median sternotomy. Ann Thorac Surg. 1992;53:1023-4.

4. Martinez-Sanz R, Fleitas MG, de la Llana R, Echevarria JR, Porras I, Gonzalez-Miranda F, et al. Submammary median sternotomy. J Cardiovasc Surg. 1990;31:578-80.

5. Brutel de la Riviere A, Brom GH, Brom AG. Horizontal submammary skin incision for median sternotomy. Ann Thorac Surg. 1981;32:101-4. 